\title{
Retrieval of Migrated Coils with Stent Retrievers: An Animal Study
}

\author{
O. Nikoubashman, R. Pjontek, M.-A. Brockmann, R. Tolba, and M. Wiesmann
}

\begin{abstract}
BACKGROUND AND PURPOSE: Coil migration is a potentially serious complication of endovascular aneurysm treatment. The aim of the study was to systematically investigate the effectiveness of coil retrieval with a stent retriever in an animal model.

MATERIALS AND METHODS: A total of 148 coils of various types and sizes were placed into arteries of varying diameters in a porcine in vivo model. Coil retrieval was performed by placing a Trevo ProVue stent retriever over the coil and trying to trap a part of the platinum coil within the stent mesh by advancing the microcatheter over the stent or simply by retrieving the stent without trying to trap the coil by advancing the microcatheter.

RESULTS: Coil retrieval was successful in 101 of 102 cases (99\%), in which trapping of the coil within the stent retriever by advancing the microcathter was applied. When we only pulled back the stent without trapping the coil, retrieval was successful in only 5 of 46 cases (11\%). Coil type, coil structure (2D versus 3D), actual coil shape in the affected vessel, investigator experience, aspiration, coil localization, and vessel diameter had no significant influence on retrieval outcome. There was no case of vessel perforation.
\end{abstract}

CONCLUSIONS: Retrieval of migrated platinum coils with a stent retriever is an effective treatment option for migrated coils when the correct technique is applied.

ABBREVIATION: GDC $=$ Guglielmi detachable coil

B rain aneurysms are the most common cause of severe and potentially lethal subarachnoid hemorrhage. Endovascular treatment with detachable coils has become a common option for both ruptured and unruptured cerebral aneurysms, especially if surgery is challenging. ${ }^{1-4}$ Coil migration is a potentially serious complication of endovascular treatment that has been reported in up to $2 \%-6 \%$ of cases. ${ }^{5,6}$ Various rescue devices have been suggested for retrieval of migrated platinum coils. However, data in the literature dealing with the effectiveness and complication rates of the respective methods are restricted to a few case reports and small case series. ${ }^{5-7}$ Our aim was to systematically investigate the effectiveness and complication rates of coil retrieval with a stent retriever in an animal model.

Received September 22, 2014; accepted after revision December 11.

From the Department of Neuroradiology (O.N., R.P., M.-A.B., M.W.) and Institute for Laboratory Animal Science and Experimental Surgery (R.T.), University Hospital Aachen, Aachen, Germany; and Medical Imaging Physics (O.N.), Institute of Neuroscience and Medicine 4, Forschungszentrum Jülich, Jülich, Germany.

Please address correspondence to Martin Wiesmann, MD, PhD, Klinik für Diagnostische und Interventionelle Neuroradiologie, Universitätsklinikum Aachen, Pauwelsstr 30, 52074 Aachen, Germany; e-mail: mwiesmann@ukaachen.de

http://dx.doi.org/10.3174/ajnr.A4240

\section{MATERIALS AND METHODS}

\section{Proof of Concept}

Proof of concept was first verified in a small in vitro study, consisting of 10 coil retrievals with a stent retriever in an in-house glass model.

\section{Animal Preparation}

All experiments were performed on 4 female German Landrace swine (weight, $\sim 60 \mathrm{~kg}$ ). The experiments were performed in accordance with the German legislation governing animal studies following the "Guide for the Care and Use of Laboratory Animals" (National Research Council, 8th edition, 2011) and the "Directive 2010/63/EU on the Protection of Animals Used for Scientific Purposes" (EU Official Journal, 2010). Official permission was granted from the governmental animal care and use office (Landesamt für Natur, Umwelt und Verbraucherschutz Nordrhein-Westfalen, Recklinghausen, Germany).

All animals received premedication with atropine $(1.5 \mathrm{~mL}$, $1 \%$; Atropin), azaperone $(0.1 \mathrm{~mL} / \mathrm{kg}$; Stresnil), and ketamine $(0.1$ $\mathrm{mL} / \mathrm{kg}, 10 \%$; Ketamin) followed by intubation and mechanical ventilation with an oxygen-air mixture. Anesthesia was maintained with propofol $(2 \%, 8-12 \mathrm{mg} / \mathrm{kg} /$ hour $)$, fentanyl (45-90 $\mu \mathrm{g} / \mathrm{kg} /$ hour $)$, and pentobarbital (160 mg/mL; Narcoren). All an- 
imals received heparin (5000 IU), acetylsalicylic acid (500 mg; aspirin), and nimodipine intravenously (2-4 mg, Nimotop). Constant saline infusion was performed in all animals to prevent dehydration. All animals had a normal vascular status.

\section{Protocol}

One experienced neurointerventionalist (M.W., 15 years of interventional experience) and 1 less experienced neurointerventionalist (O.N., 1 year of interventional experience) performed all procedures in random order. The type of coil and the target vessels were randomly assigned. When coils were placed in a target vessel, final coil localization was left to blood flow and was not manipulated by the investigators. Every coil type was retrieved by using the standard retrieval technique and the advanced retrieval technique with intentional trapping of the coil as described in detail below. Experiments were performed with and without aspiration via the guide catheter during retrieval in alternating order according to a predefined protocol. Consequently, every coil type was retrieved with and without aspiration and with and without intentional trapping, respectively.

\section{Procedure}

All procedures were performed under fluoroscopy by using a single-plane angiography system (Axiom Artis dFC; Siemens, Erlangen, Germany). Iopamidol (Solutrast, $300 \mathrm{mg} / \mathrm{mol}$, diluted in an 8:2 ratio with a saline solution; Bracco Imaging, Konstanz, Germany) was used as a contrast agent.

The target vessels (subclavian artery and its first branches) were reached by using a $6 \mathrm{~F}$ Envoy MPD guiding catheter with an angled tip (Codman \& Shurtleff, Raynham, Massachusetts) supported by a 0.035 -inch standard angled Radifocus Guide wire (Terumo, Tokyo, Japan).

Target vessels were catheterized with an Excelsior SL-10 microcatheter (Boston Scientific, Natick, Massachusetts) over a Synchro-2 soft 14 microguidewire (Boston Scientific). A coil was placed and detached by using its respective detaching mechanism. We applied the following coils: Guglielmi detachable coil (GDC)-10 360 Standard $(4 \mathrm{~mm} \times 7 \mathrm{~cm})$, GDC-10 3D Standard $(4$ $\mathrm{mm} \times 8 \mathrm{~cm})$, GDC-10 Soft $2 \mathrm{D} \mathrm{SR}(3 \mathrm{~mm} \times 6 \mathrm{~cm}$ and $6 \mathrm{~mm} \times 8$ $\mathrm{cm})$, GDC-10 Soft SR $(3 \mathrm{~mm} \times 6 \mathrm{~cm}, 3 \mathrm{~mm} \times 14 \mathrm{~cm}$, and $6 \mathrm{~mm} \times$ $11 \mathrm{~cm})$, GDC-10 UltraSoft $(3 \mathrm{~mm} \times 6 \mathrm{~cm}$ and $4 \mathrm{~mm} \times 8 \mathrm{~cm})$, Matrix $^{2}$ 2D Soft SR $(6 \mathrm{~mm} \times 10 \mathrm{~mm})$, and Matrix ${ }^{2}$ 3D Standard $(3 \mathrm{~mm} \times 6 \mathrm{~cm}$ and $4 \mathrm{~mm} \times 8 \mathrm{~cm}$ ) (all Stryker, Kalamazoo, Michigan).

After a coil migrated to its final position, retrieval was performed by using a Trevo ProVue (4-mm-diameter) stent retriever (Stryker) in combination with its supplied microcatheter (Trevo MC18; Stryker). The basic steps were as follows: The coil was passed with the microwire, over which the microcatheter was advanced. After removal of the microwire, the stent retriever was advanced and positioned so that the coil was located in the first two-thirds of the stent retriever. Next, the stent retriever was unsheathed. Retrieval was performed in 2 different manners: 1) Standard thrombectomy technique: the microcatheter and stent retriever were simultaneously pulled into the guiding catheter, without intentional trapping of the coil. 2) A retrieval technique as described by O'Hare et $\mathrm{al}^{8}$ : the microcatheter and stent re-

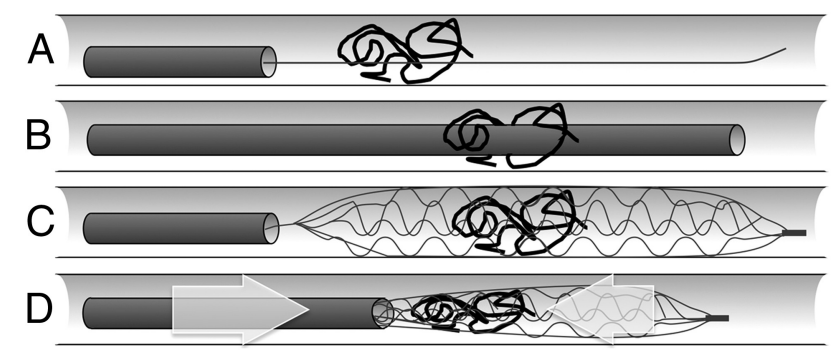

FIG 1. Illustration of the advanced retrieval technique with intentional trapping of the coil: The coil is passed with the microwire $(A)$ followed by the microcatheter $(B)$. Note that displacement of the coil might be encountered. The stent retriever should cover the coil with its distal two-thirds $(C)$. The microcatheter is pushed forward while gently pulling back the stent retriever at the same time $(D)$ to trap the coil. A resistance signals that the coil has been locked within the stent. At this point, both the microcatheter and the stent retriever are carefully withdrawn under fluoroscopic control.

triever were simultaneously pulled into the guiding catheter, with intentional trapping of the coil (see below).

Retrieval was considered successful only when complete coil retrieval was achieved. Retrieval duration was defined as the time between positioning of the microwire and retrieval of the system. An aspiration pump (Penumbra, Alameda, California) connected to the guiding catheter provided constant aspiration during retrieval in selected cases (see above). After each extraction, the vessels were examined for occlusion, vasospasm, and perforation in DSA.

\section{Advanced Coil-Retrieval Technique}

While delivery and unsheathing of the stent retriever are identical to the technique used for thrombectomy in stroke, there are important differences. When one unsheathes the stent retriever, the coil should be positioned within the first two-thirds of the stent retriever (Fig 1C). Note that displacement of the coil may be encountered when positioning the microcatheter (Fig $1 A,-B$ ). After one unsheathes the stent retriever (Fig $1 A-C$ ), the aim is to lock parts of the coil within the stent retriever. Therefore, the stent retriever is partially resheathed by carefully pushing the microcatheter and slightly pulling the stent retriever at the same time (Fig 1D). A resistance, which might be elastic at first, signals that parts of the coil have been caught within the stent, making further resheathing impossible. If there is no resistance, the procedure should be repeated because the coil is most likely not sufficiently locked within the stent. Although trapping the coil usually fixates the stent retriever within the microcatheter, the stent retriever should be secured against movement in relation to the microcatheter.

Sometimes it might be difficult (and sometimes impossible) to pass the coil with the microcatheter. In these cases, we placed the microcatheter proximal to the coil and carefully pushed the stent retriever into the coil (Fig 2). Even though we used this technique 16 times without complications, it most probably is associated with an increased perforation risk. Therefore, it should only be performed after careful risk-benefit analysis.

Once the coil is trapped, both microcatheter and stent retriever should be carefully withdrawn under fluoroscopic control (Fig 3).

AJNR Am J Neuroradiol 36:1162-66 Jun 2015 www.ajnr.org 1163 


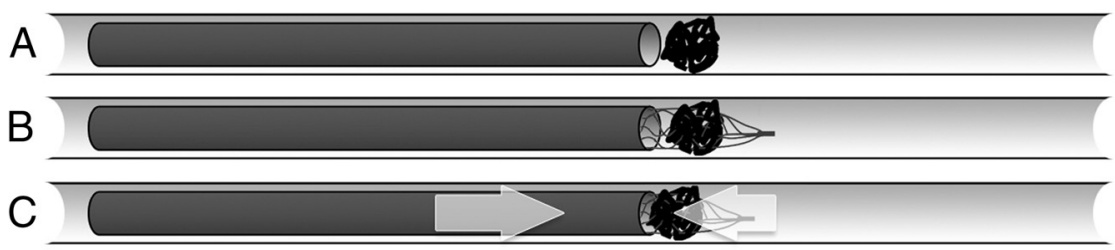

FIG 2. Illustration of the retrieval technique applied if passage of the coil with the microcatheter is not possible. In this case, the microcatheter should be positioned directly proximal to the coil $(A)$. The stent retriever is carefully pushed into the coil $(B)$ and the microcatheter is pushed forward while gently pulling back the stent retriever at the same time (C) to trap the coil. A resistance signals that the coil has been locked within the stent. The microcatheter and the stent retriever are then withdrawn as described in Fig 1. Note that this technique is likely to be associated with an increased risk of vessel perforation and thus should only be performed after careful risk-benefit analysis.

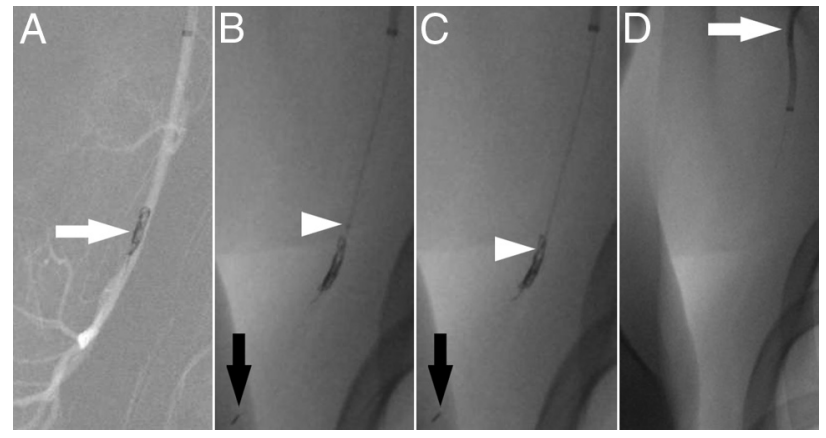

FIG 3. $A$ GDC-10 Soft $\mathrm{SR}$ coil $(3 \mathrm{~mm} \times 6 \mathrm{~cm})$ migrated into a musculoskeletal branch of the axillary artery $(A$, arrow). The stent retriever is unsheathed with the distal two-thirds of the stent retriever covering the coil $(B)$. The distal tip of the stent retriever is marked with a black arrow ( $B$ and $C$ ). The microcatheter is being pushed ( $B$ and $C$, white arrowhead) while slightly pulling the stent retriever backward until a resistance is felt to trap the coil. Once the coil is locked, both the microcatheter and the stent retriever are carefully withdrawn into the guiding catheter $(D$, arrow).

\section{Statistical Analyses}

Standard statistical tests (Student $t$ test, Pearson $\chi^{2}$ test, Fisher exact test) were performed when applicable. $P$ values under the $\alpha$ level of .05 were significant. All statistical analyses were performed with SPSS 20 software (IBM, Armonk, New York).

\section{RESULTS}

\section{Preliminary In Vitro Experiment}

In a preliminary experiment, a GDC-10 Soft SR $(3 \mathrm{~mm} \times 6 \mathrm{~cm})$ coil was retrieved 5 times with a Solitaire stent (Covidien, Irvine, California) and 5 times with a Trevo ProVue stent retriever in an in-house glass model. The coil was intentionally trapped and successfully retrieved in all 10 experiments.

\section{Animal Study}

A total of 148 extractions were performed in 4 swine. Each investigator performed 74 retrievals. The advanced retrieval technique with intentional trapping of the coil was applied in 102 experiments $(69 \%)$. Retrieval was assisted by aspiration in 71 of 148 cases (48\%). In 132 cases (89\%), it was possible to pass the coil with the microcatheter, and the stent retriever was unsheathed over the coil by pulling back the microcatheter. In 16 cases (11\%), it was not possible to pass the coil with the microcatheter, and the stent retriever was carefully pushed over the coil (Fig 2). Mean duration of retrieval was $1.35 \pm 0.637$ minutes (range, 1-3 minutes).

Retrieval was successful in $106(72 \%)$ of all 148 cases. Overall, retrieval failed in 42 cases. More precisely, retrieval was not possible at all in 22 of 42 unsuccessful cases (15\%), while a coil was initially captured but lost in the remaining 20 of 42 unsuccessful cases (14\%). Retrieval was successful in 101 of 102 cases (99\%) when the advanced retrieval technique with intentional trapping of the coil was applied (Fig 3). One of the 20 cases with loss of an initially captured coil occurred when intentional trapping of the coil failed to fixate the coil sufficiently. When applying the standard retrieval technique (ie, retrieval without trapping of the coil), retrieval was successful in only 5 of 46 cases (11\%).

There was no case of vessel perforation, vasospasm, or occlusion.

\section{Localization and Specification of Used Coils}

Coil localization was in the distal subclavian artery in 52 cases $(35 \%)$, in the internal thoracic artery in 34 cases $(23 \%)$, in the vertebral artery in 12 cases (8\%), and in musculoskeletal branches of the axillar artery in 50 cases (34\%). Mean vessel diameter was as follows—subclavian artery: $3.4 \pm 1.2 \mathrm{~mm}$; internal thoracic artery: $2.2 \pm 0.39 \mathrm{~mm}$; vertebral artery: $2.8 \pm 0.45 \mathrm{~mm}$; and musculoskeletal branches of the axillar artery: $2.7 \pm 0.72 \mathrm{~mm}$. Mean vessel diameter of all arteries was $2.8 \pm 0.95 \mathrm{~mm}$ (range, $1.6-5.5 \mathrm{~mm})$.

The frequency of coil retrieval was as follows-GDC-10 Standard 360: 20 times; GDC-10 3D Standard: 22 times; GDC-10 Soft 2D SR: 22 times; GDC-10 Soft SR: 20 times; GDC-10 ULTRASOFT: 22 times; Matrix ${ }^{2}$ 2D Soft SR: 22 times; and Matrix ${ }^{2}$ 3D Standard: 22 times.

Coil diameter was larger than the arterial diameter in 126 cases $(85 \%)$ and equal to the arterial diameter in the remaining 22 cases (15\%). Coils were in their respective designated shape in 33 cases (22\%) and elongated in the remaining 115 cases (78\%). Mean coil diameter was $4.3 \pm 1.252 \mathrm{~mm}$ (range, $3-6 \mathrm{~mm}$ ) and mean coil length was $7.9 \pm 1.7 \mathrm{~cm}$ (range, $6-14 \mathrm{~cm}$ ).

\section{Retrieval Rates and Confounding Factors}

Retrieval was significantly more likely when the advanced retrieval technique with intentional trapping of the coil was applied $\left(P<.001\right.$, Pearson $\chi^{2}$ test $)$. Considering all 148 experiments, successful retrieval was more likely for small and short coils $(P=$ .041 and .014 , respectively, Student $t$ test). However, coil size and length had no significant influence, when applying the advanced retrieval technique $(P=.828$ and $P=.638$, respectively; Student $t$ test).

Coil type ( $P=.476$, Pearson $\chi^{2}$ test $)$, coil structure (2D versus 3D) $\left(P=.828\right.$, Pearson $\chi^{2}$ test $)$, actual coil configuration (designated shape versus elongated shape) $\left(P=.142\right.$, Pearson $\chi^{2}$ test $)$, investigator experience $\left(P=1.00\right.$, Pearson $\chi^{2}$ test $)$, aspiration $\left(P=.155\right.$, Pearson $\chi^{2}$ test $)$, coil localization $\left(P=.218\right.$, Pearson $\chi^{2}$ 
test), and mean vessel diameter $(P=.508$, Student $t$ test $)$ had no significant influence on retrieval success rates.

\section{DISCUSSION}

Coiling of wide-neck, giant, or very small aneurysms can be challenging. Even though stent or balloon-assisted techniques reduce the risk of complications, coil migration has been reported to occur in up to $2 \%-6 \%$ of cases. ${ }^{5,6}$ Whereas marginally herniated coils in an otherwise sufficiently embolized aneurysm are usually treated with temporary oral antiplatelet therapy until endothelialization of the herniated coil segment is complete, more prominently herniated coils can be adapted to the vessel wall by using a stent and likewise need to be treated with temporary oral antiplatelet therapy. ${ }^{9,10}$ Migrated coils, however, usually need to be retrieved immediately because they pose a high risk for subsequent vessel occlusion causing cerebral ischemia or death. This is why neurointerventionalists should always be prepared for immediate retrieval of migrated coils. However, many neurointerventionalists lack sufficient experience with dedicated retrieval devices (eg, "snare" devices or Alligator Retrieval Device; Chestnut Medical Technologies, Menlo Park, California). Moreover, dedicated retrieval devices may not be available in all neurovascular centers. Most neurointerventionalists, however, have become familiar with stent retrievers that are being used in acute stroke treatment. Thus, the results of our investigation might prove helpful and could be a viable way for most neurointerventionalists to retrieve a migrated coil.

There is no established standard procedure for the retrieval of migrated coils. Data dealing with endovascular coil retrieval consist of case reports and small case series.

Common retrieval techniques involve endovascular retrieval devices, namely the Alligator device or so-called snare devices, which have also been referred to as "lasso" devices (eg, Amplatz goose neck snares and microsnares; Covidien, Irvine, California). ${ }^{5,7,11-16}$ Coil retrieval with a snare or lasso device was successful in 28 of 33 (85\%) cases..$^{5,7,11-19}$ Coil retrieval with an Alligator device was successful in 1 of 2 reported cases. ${ }^{14,20}$ In past years, coil retrieval with stent retrievers, namely the Solitaire, the Trevo, and the Catch system (Balt, Montmorency, France) was reported. ${ }^{7,20,21}$ All 18 reported coil retrievals with these devices were successful. ${ }^{7,20,21}$ Coil retrieval with a Merci retriever (Concentric Medical, Mountain View, California) was successful in all 3 reported cases. ${ }^{22-24}$ Less common techniques involve trapping of a migrated coil between 2 wires, ${ }^{17,25}$ manual aspiration, ${ }^{26}$ and coil retrieval with an Enterprise self-expanding stent (Codman \& Shurtleff). ${ }^{27}$

Overall, coil retrieval with a stent retriever device appears to be an effective treatment option, regardless of the stent retriever design. ${ }^{7,19-21}$ Consistent with our own experience, coil retrieval with a stent retriever is reported to be less challenging and to require less manipulation than coil retrieval with snare devices and the Alligator device. ${ }^{7}$ Especially, access to distal or curved vessels with the Alligator device can be very challenging, given its relatively stiff tip.

In our series, coil retrieval was successful in 101 of 102 cases (99\%) when trapping of the coil within the stent was applied, regardless of coil type, coil structure (2D versus $3 \mathrm{D})$, actual coil shape in the affected vessel, investigator experience, additional aspiration, coil localization, and the diameter of the affected artery. When intentional trapping was desired, the only case with a lost coil occurred when the investigator noticed no resistance when the stent retriever and microcatheter were moved against each other.

There was no case of vasospasm or immediate vessel occlusion, which is most likely due to premedication with acetylsalicylic acid and nimodipine in our experiments. Because our swine model does not allow the detection of small thrombotic emboli during coil withdrawal, we recommend constant proximal aspiration during coil withdrawal and we advise the administration of acetylsalicylic acid or a glycoprotein IIb/IIIa antagonist to minimize the risk of local thrombosis and/or thrombotic embolism. In addition, intravenous administration of nimodipine should be considered if vasospasms are encountered. Furthermore, hypertension should be induced whenever possible to counteract reduced blood flow in the occluded territory. We also found that it is usually not possible to fully resheath the stent retriever due to the trapped coil. The exposed end of the stent retriever might get stuck during withdrawal when the treated aneurysm or a preexisting stent have to be passed. A distal-access guiding catheter covering the stent retriever should be considered in these cases.

\section{Limitations}

Coil retrieval is an emergency procedure that cannot be examined systematically in humans. Even though data from an animal model cannot be transferred to humans without restrictions (eg, that peripheral swine vessels might be less susceptible to perforations compared with human cerebral vessels or that our swine model did not allow detection of thrombotic emboli), swine represent an established animal model for endovascular procedures, given their comparable vascular anatomy and coagulation. ${ }^{28}$ To anticipate differences between humans and swine, we examined coil retrieval in vessels that are comparable with affected human vessels with regard to size, blood flow, and accessibility. A further limitation is that an experiment that involves all possible combinations of coils, vessels, and stent retrievers is practically impossible. Conscious of this limitation, we decided to retrieve various coils in various settings while keeping the rest of the study standardized to maximize statistical validity.

\section{CONCLUSIONS}

The results from our systematic animal study imply that stent retrievers can be considered an effective treatment option for retrieval of migrated coils in a vast variety of settings.

\section{ACKNOWLEDGMENTS}

The authors thank Anna Woitok and Thaddäus Stopinski for their skillful technical assistance during the animal studies.

Disclosures: Martin Wiesmann—UNRELATED: Consultancy: Stryker Neurovascular, Philips Healthcare; Payment for Lectures (including service on Speakers Bureaus): Boston Scientific, Bracco, Siemens, Stryker; Payment for Development of Educational Presentations: Abbott, ${ }^{*}$ ab medica, ${ }^{*}$ Acandis, ${ }^{*}$ Bayer, ${ }^{*}$ Bracco, ${ }^{*}$ B. Braun, ${ }^{*}$ Codman Neurovascular, ${ }^{\star}$ Covidien, ${ }^{\star}$ Dahlhausen, ${ }^{\star}$ MicroVention, ${ }^{\star}$ Penumbra, ${ }^{*}$ Phenox, ${ }^{\star}$ Philips Healthcare, ${ }^{*}$ St. Jude, ${ }^{*}$ Stryker. ${ }^{*}$ Money paid to the institution. 


\section{REFERENCES}

1. Molyneux AJ, Kerr RS, Yu LM, et al. International Subarachnoid Aneurysm Trial (ISAT) of neurosurgical clipping versus endovascular coiling in 2143 patients with ruptured intracranial aneurysms: a randomised comparison of effects on survival, dependency, seizures, rebleeding, subgroups, and aneurysm occlusion. Lancet 2005;366: 809-17

2. van Gijn J, Kerr RS, Rinkel GJ. Subarachnoid haemorrhage. Lancet 2007;369:306-18

3. Chalouhi N, Tjoumakaris S, Gonzalez LF, et al. Coiling of large and giant aneurysms: complications and long-term results of 334 cases. AJNR Am J Neuroradiol 2014;35:546-52

4. Huang Q, Liu J, Zhao R, et al. The safety and efficacy of stenting in the treatment of complex posterior cerebral artery aneurysms: a seven-case report and literature review. Clin Neuroradiol 2013;23: 175-87

5. Lampmann LE, Sluzewski M, Van Rooij WJ. Retrieval of malpositioned, dislocated or fractured Guglielmi detachable coils from intracranial vessels: a report of seven cases. Interv Neuroradiol 2000; 6:251-56

6. Ding D, Liu KC. Management strategies for intraprocedural coil migration during endovascular treatment of intracranial aneurysms. J Neurointerv Surg 2014;6:428-31

7. Leslie-Mazwi TM, Heddier M, Nordmeyer H, et al. Stent retriever use for retrieval of displaced microcoils: a consecutive case series. AJNR Am J Neuroradiol 2013;34:1996-99

8. O'Hare AM, Rogopoulos AM, Stracke PC, et al. Retrieval of displaced coil using a Solitaire(R) stent. Clin Neuroradiol 2010;20: 251-54

9. Schütz A, Solymosi L, Vince GH, et al. Proximal stent fixation of fractured coils: technical note. Neuroradiology 2005;47:874-78

10. Luo CB, Chang FC, Teng MM, et al. Stent management of coil herniation in embolization of internal carotid aneurysms. AJNR Am J Neuroradiol 2008;29:1951-55

11. Dinc H, Kuzeyli K, Kosucu P, et al. Retrieval of prolapsed coils during endovascular treatment of cerebral aneurysms. Neuroradiology 2006;48:269-72

12. Fiorella D, Albuquerque FC, Deshmukh VR, et al. Monorail snare technique for the recovery of stretched platinum coils: technical case report. Neurosurgery 2005;57(1 suppl):E210; discussion E210

13. Koseoglu K, Parildar M, Oran I, et al. Retrieval of intravascular foreign bodies with goose neck snare. Eur J Radiol 2004;49:281-85

14. Henkes H, Lownes S, Preiss H, et al. A new device for endovascular coil retrieval from intracranial vessels: Alligator retrieval device. AJNR Am J Neuroradiol 2006;27:327-29

15. Prestigiacomo CJ, Fidlow K, Pile-Spellman J. Retrieval of a fractured Guglielmi detachable coil with use of the Goose Neck snare 'twist' technique. J Vasc Interv Radiol 1999;10:1243-47

16. Watanabe A, Hirano K, Mizukawa K, et al. Retrieval of a migrated detachable coil: case report. Neurol Med Chir (Tokyo) 1995;35: $247-50$

17. Lee CY. Use of wire as a snare for endovascular retrieval of displaced or stretched coils: rescue from a technical complication. Neuroradiology 2011;53:31-35

18. Raftopoulos C, Goffette P, Billa RF, et al. Transvascular coil hooking procedure to retrieve an unraveled Guglielmi detachable coil: technical note. Neurosurgery 2002;50:912-14; discussion 914-15

19. Zoarski GH, Bear HM, Clouston JC, et al. Endovascular extraction of malpositioned fibered platinum microcoils from the aneurysm sac during endovascular therapy. AJNR Am J Neuroradiol 1997;18: 691-95

20. Liu KC, Ding D, Starke RM, et al. Intraprocedural retrieval of migrated coils during endovascular aneurysm treatment with the Trevo Stentriever device. J Clin Neurosci 2014;21:503-06

21. Hopf-Jensen S, Hensler HM, Preiss M, et al. Solitaire(R) stent for endovascular coil retrieval. J Clin Neurosci 2013;20:884-86

22. Kung DK, Abel TJ, Madhavan KH, et al. Treatment of endovascular coil and stent migration using the Merci retriever: report of three cases. Case Report Med 2012;2012:242101

23. O'Hare A, Brennan P, Thornton J. Retrieval of a migrated coil using an X6 MERCI device. Interv Neuroradiol 2009;15:99-102

24. Vora N, Thomas A, Germanwala A, et al. Retrieval of a displaced detachable coil and intracranial stent with an L5 Merci retriever during endovascular embolization of an intracranial aneurysm. J Neuroimaging 2008;18:81-84

25. Standard SC, Chavis TD, Wakhloo AK, et al. Retrieval of a Guglielmi detachable coil after unraveling and fracture: case report and experimental results. Neurosurgery 1994;35:994-98; discussion 999

26. Stidd DA, Johnson AK, Lopes DK. Manual aspiration technique to retrieve a prematurely detached coil during cerebral aneurysm embolization. Neurointervention 2014;9:21-25

27. Wakhloo AK, Gounis MJ. Retrievable closed cell intracranial stent for foreign body and clot removal. Neurosurgery 2008;62(5 suppl 2): ONS390-93; discussion ONS393-94

28. Bouzeghrane F, Naggara $\mathrm{O}$, Kallmes $\mathrm{DF}$, et al. In vivo experimental intracranial aneurysm models: a systematic review. AJNR Am J Neuroradiol 2010;31:418-23 